\title{
Optimal Endoscopic Management of Anastomotic Strictures After Double- Biliary Reconstruction in Right Lobe Living-Donor Liver Transplantation
}

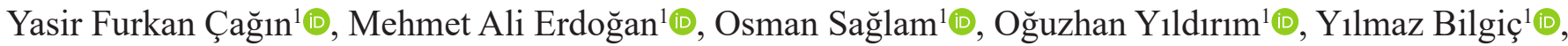 \\ Ahmet Kadir Arslan²®, Kemal Barış Sarıcı ${ }^{3 \oplus}$, Sezai Yılmaz ${ }^{3}$
}

\author{
${ }^{1}$ Department of Gastroenterology, İnönü University School of Medicine, Malatya, Turkey \\ ${ }^{2}$ Department of Biostatistics and Medical Informatics, İnönü University School of Medicine, Malatya, Turkey \\ ${ }^{3}$ Department of General Surgery, İnönü University School of Medicine, Malatya, Turkey
}

\begin{abstract}
Background: There is no consensus on the optimal drainage technique in the management of biliary anastomotic strictures occurring after right-lobe living-donor liver transplantation (RL LDLT).

Aims: To investigate whether there is a superiority between unilateral and bilateral drainage groups in terms of efficacy and safety of biliary drainage in RL LDLT patients undergoing double-biliary reconstruction.

Study Design: Retrospective Cohort

Methods: Between January 2009 and August 2019, 1693 patients underwent RL LDLT. Of these, 182 patients who developed biliary anastomotic strictures out of the 306 patients who had double-biliary reconstruction, were included in the study. One hundred fifty-five patients with technical success were divided into 2 groups as unilateral $(\mathrm{n}=116)$ and bilateral $(\mathrm{n}=39)$ drainage groups. The groups were compared in terms of variable parameters such as clinical success, additional procedure, post-ERCP complication, procedures after clinical failure, hospital stay, mortality, and survival.
\end{abstract}

Results: The clinical success was higher in the bilateral group (70\% vs. $82 \%, P=.201)$. In the initial and the follow-up periods, a total of 44 $(38 \%)$ patients in the unilateral group were switched to the bilateral drainage group due to the increased need for stenting. The placement of a stent successfully solved the problem only in $28 \%(32 / 117)$ of the patients in the unilateral group, while this rate was $44 \%(17 / 39)$ in the bilateral group. The median follow-up time of both groups was 42 months, and was equal. The number of stent-free follow-up patients in the unilateral drainage group was less than that in the bilateral drainage group (4 and 7, respectively).

Conclusion: An active attempt should be made for bilateral drainage in patients with biliary anastomotic stricture following RL LDLT. However, for patients in whom bilateral drainage is not possible, unilateral drainage may be recommended, with the placement of a maximum number of stents following primary biliary balloon dilatation, depending on the degree of stricture.

\section{INTRODUCTION}

Living-donor liver transplantation (LDLT) is frequently performed in many countries, as the low rate of organ donation has lengthened the waiting lists and is also the cause for increased mortality. More than $90 \%$ of liver transplantations (LT) are performed with grafts donated by the patients' relatives. ${ }^{1}$ In adults, LDLT is performed on the adult right lobe (RL), and to a lesser extent, the left lobe (especially in pediatric patients). In addition, LDLT contributes to lowering the rate of mortality, ${ }^{2}$ with extensive donor screening, optimization of transplantation time, and minimal cold ischemia time,$^{3}$ but is also accompanied by disadvantages such as high cost and risk to donor health. ${ }^{4,5}$

During the reconstruction of the biliary tract during LDLT, the duct-to-duct anastomosis (DDA) technique is the most frequently used due to its potential advantages such as shorter operation time, more physiological sphincter function, fewer septic complications, and the possibility of endoscopic evaluation of the biliary tract in case of the potentially possible complications. ${ }^{6,7} \mathrm{It}$ has been a major concern that despite this advantage, bile duct obstruction is more common in the right-lobe living-donor liver

Corresponding author: Yasir Furkan Çağın, Department of Gastroenterology, İnönü University School of Medicine, Malatya, Turkey e-mail: yafur@hotmail.com

Received: June 18, 2021 Accepted: August 26, 2021 Available Online Date: October 4, 2021 • DOI: 10.5152/balkanmedj.2021.21692

Available at www.balkanmedicaljournal.org

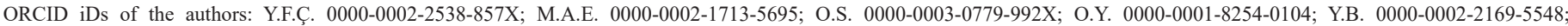
A.K.A. 0000-0001-8626-9542; K.B.S. 0000-0001-9595-1906; S.Y. 0000-0002-8044-0297.

Cite this article as:

Çağın YF, Erdoğan MA, Sağlam O, et al. Optimal endoscopic management of anastomotic strictures after double-biliary reconstruction in right lobe living-donor liver transplantation. Balkan Med J.; 2021; 38(6):348-356.

Copyright@Author(s)-Available online at http://balkanmedicaljournal.org/ 
transplant (RL LDLT). Biliary strictures account for about $40 \%$ of all biliary complications after LT. Approximately $70-90 \%$ of these occur in the anastomosis region. The studies show that the incidence of anastomotic strictures varies between $4 \%$ and $16 \% .^{8-10}$

Although there is no validated therapeutic algorithm, several options have been used for treatment, including surgery and endoscopic and percutaneous transhepatic intervention. In the past 2 decades, the primary treatment of anastomotic strictures has been predominantly transitioned to endoscopic treatment. ${ }^{11}$ For this, stent placement is frequently performed. It is observed that when stent placement is performed after biliary balloon dilatation, permanent successful results are achieved in approximately $63-80 \%$ of patients with anastomotic stricture. ${ }^{12,13}$

In a study, it was shown that the placement of progressively more stents following balloon dilatation in anastomotic strictures after LDLT provided continuous patency of the biliary anastomoses in approximately $84 \%$ of patients. ${ }^{14}$ This result makes endoscopic therapy the first option of treatment for post-LDLT anastomotic strictures. However, endoscopic treatment for strictures developing after RL LDLT, DDA is more difficult than for strictures developing after deceased-donor liver transplant (DDLT). The major reason for this appears to be 2 anastomosis regions that connect both the right anterior segmental branch (RASD) and the right posterior segmental branch (RPSD) to the common hepatic canal of the recipient, and that the confluence of the right main bile branch appears to be narrower than the left main bile branch. ${ }^{15,16}$ Therefore, endoscopic treatment fails in $25-40 \%$ of patients. Percutaneous transhepatic biliary drainage (PTBD) is usually performed successfully in these patients. ${ }^{17}$ In most patients with anastomotic stricture, stent replacement is performed at every 3-month interval in ERCP sessions, to avoid stent occlusion and cholangitis. According to the fluoroscopic findings that the operator observes with the contrast drainage during the procedure, the multiple-stent placement with a diameter of $7 \mathrm{Fr}$ to $10 \mathrm{Fr}$ are performed after $6-10 \mathrm{~mm}$ biliary balloon dilatation when necessary. ERCP sessions should continue for 12-24 months. ${ }^{18-20}$ It has been shown that an increasing number of stents can be used in each session to achieve maximum benefit. ${ }^{19,21}$

Although an increasing number of stenting procedures are recommended for maximally optimal bile drainage of each stricture, alternative options have been explored, owing to the increased processing time and the possibility of complications with such an approach. ${ }^{22}$ However, since there are limited studies in LDLT patients, ${ }^{23}$ we wanted to experience the same situation in a highvolume LDLT center like ours. Therefore, we planned this study to investigate which technical procedure is superior in terms of efficacy and safety of biliary drainage in biliary double anastomotic strictures occurring in RL LDLT patients.

\section{MATERIAL AND METHODS}

\section{The Characteristics of the Participating Patients}

The patients included in the study group had undergone RL LDLT between January 2009 and August 2019 and were over 18 years old. The data of a total of 1693 patients were analyzed retrospectively from the registered database. When the degree of donor relation of all patients was examined, most of the livingdonor grafts were from the children of the recipients, the remaining grafts were from husbands (7\%), nephews (4\%), and wives (7\%). Among these patients, 1236 patients with single anastomosis, 54 with hepaticojejunostomy and 97 with insufficient data were excluded from the study. One hundred eighty-two patients with suspected acute cholangitis or biliary anastomotic stricture were examined with endoscopic retrograde cholangiopancreaticography (ERCP) after obtaining an informed consent form. Based on the cholangiographic findings, 155 patients with double anastomosis and strictures in both anastomoses were included in this study and followed-up by clinical, laboratory, and radiological evaluation (Figure 1). The patients underwent more than one session of ERCP during the follow-up period. This study was carried out with the approval of the ethics committee (2020/789). Informed consent was not obtained because this study was a retrospective study. This study included right-lobe (RL) LDLT patients with double anastomoses and strictures in both the anastomoses.

\section{Data Screening}

Based on the data of patients from the computer records system, the demographic features, Charlson comorbidity index, reasons for LT, liver cirrhosis etiology, LT-related donor age, operation time, warm and cold ischemia times, duration of the initial stricture, the main

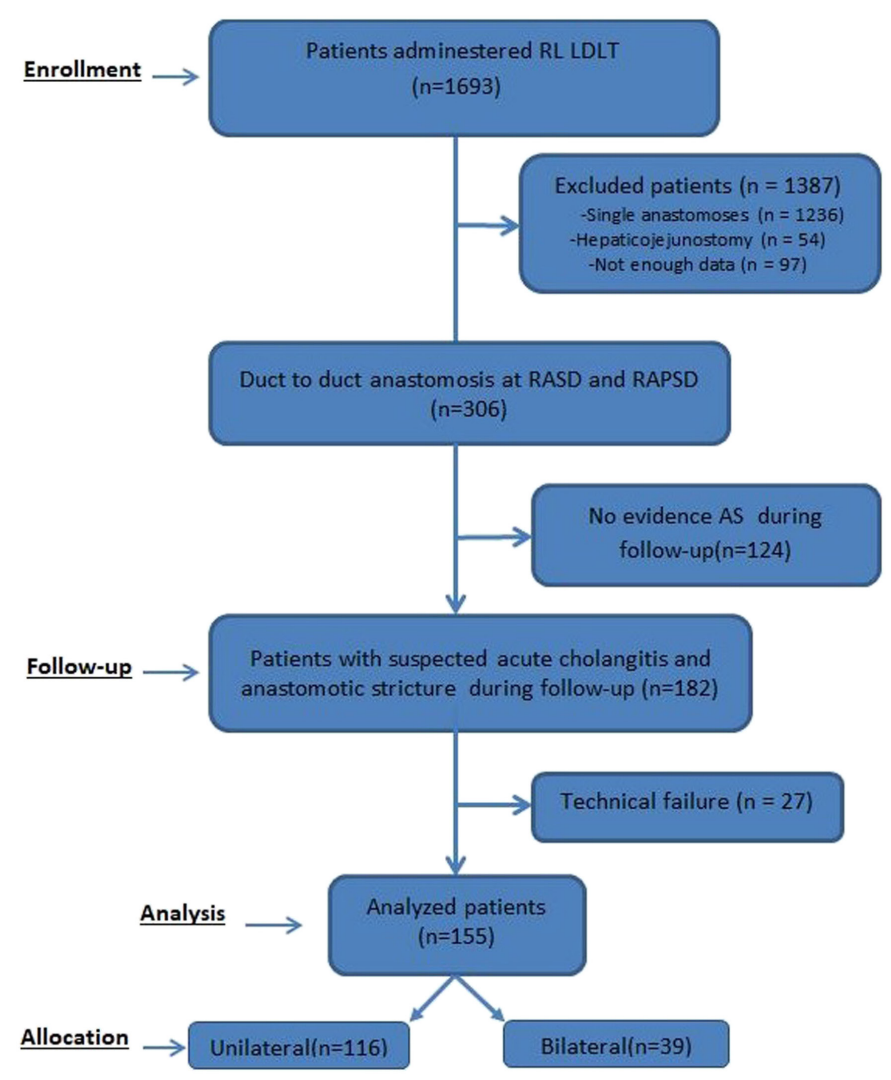

FIG. 1. The flowchart of the analyzed registered patients. 
clinical findings of biliary stricture, the laboratory values before the initial ERCP, fluoroscopic and endoscopic findings, and treatment information during the initial ERCP were examined. After LT, patients were followed-up periodically to detect any complications by physical examination, laboratory tests, and radiological imaging methods. Magnetic resonance cholangiopancreatography (MRCP) or contrast computed tomography (CT) and/or transabdominal ultrasonography (USG) were performed within 1 week, and a control CT scan at the third month after operation. In the absence of any abnormality, the next control was completed by a CT scan 6 months later. In the presence of any findings suggesting acute cholangitis during follow-up, emergency imaging procedures were performed.

Before the initial ERCP, all patients were evaluated by their symptoms, body temperature, physical examination, and laboratory tests such as complete blood count, C-reactive protein (CRP), and liver function test (LFT). The ERCP procedure was performed in patients with suspected biliary anastomotic stricture or acute cholangitis, after the diagnosis was confirmed by any imaging method (MRCP, CT, USG). Firstly, the diagnosis of anastomotic stricture was confirmed according to the cholangiogram in fluoroscopy by the ERCP procedure. Biliary anastomotic stricture was classified according to the fluoroscopic findings during the ERCP procedure (Figure 2). ${ }^{24,25}$ Then, an intraprocedural roadmap for the necessary intervention was determined.

\section{Procedures Applied}

The ERCP was performed with video duodenoscopes (GIF-Q150, TJF-Q180V; Olympus Optical Co., Ltd., Tokyo, Japan) under sedation with midazolam and propofol. The patient's biliary tract was cannulated through the guide wire in the major duodenal papilla. If direct cannulation was unsuccessful after several attempts, cannulation was achieved with precut papillotomy. After cannulation, the morphology of the biliary strictures was determined according to the cholangiogram findings. If the visualized stricture's lumen diameter was $>2 \mathrm{~mm}$, it was classified as wide type; if $\leq 2 \mathrm{~mm}$, narrow type; and strictures in which the proximal duct could be visualized but the stricture area could not be visualized, or in which the proximal duct could not be visualized, were categorized as separate type. According to the angle between the proximal and distal ducts, there are 3 divisions, as $0-30,<90$ and S-shaped. ${ }^{26}$
Then, a guide wire was inserted through the biliary anastomotic structure and as many plastic stents as possible (diameter 7.0 Fr and $10.0 \mathrm{Fr}, 12-18 \mathrm{~cm}$ in length) were placed. If the anastomotic stricture was too tight, stenting was performed after dilation with a bougie dilation catheter ( $7 \mathrm{Fr}$ ) or a biliary dilation balloon $(4-6 \mathrm{~mm}$ wide, $2 \mathrm{~cm}$ long). The decision of whether RASD and/or RPSD would provide sufficient bile drainage was made at the discretion of the operator. In the initial ERCP, factors affecting the procedure time, such as endoscopic sphincterotomy (EST), precut papillotomy, stone removal, biliary balloon dilatation, and biliary stenting were evaluated. Four hours after the ERCP procedure, complete blood count, laboratory tests including amylase and lipase, and if necessary, a standing abdominal x-ray were performed. The day after the ERCP, these tests were repeated with LFTs. The complications after ERCP were evaluated according to the patient's symptoms, physical examination, and laboratory findings. In case of ineffective drainage, ERCP and/or percutaneous transhepatic biliary drainage (PTBD) were attempted. The repetition of these procedures was performed based on the clinical, laboratory, and/or imaging findings of the patients during follow-up.

\section{The Groups' Post-Processing Design}

According to the initial ERCP findings, the patients were divided into 2 separate groups - the unilateral $(n=116)$ and the bilateral drainage $(n=39)$ groups. Patients with stent placement in only one of RASD or RPSD were assigned to the unilateral drainage group and patients who underwent stenting on both branches were assigned to the bilateral drainage group.

The primary endpoint for stricture resolution was defined according to LFT-based radiographic and/or clinical improvement $(>50.0 \%$ reduction in baseline within 4 weeks), whether it was with unilateral or bilateral stenting (or dual stenting). The secondary endpoint was considered to be the continuation of stent-free well-being after stent removal. The primary outcome was the proportion of patients resolved by unilateral drainage during follow-up. Patients who were transferred to the bilateral drainage group were identified by ERCP and/or PTBD in case of clinical failure during follow-up periods. Clinical success in this situation was defined as a secondary outcome. Comparisons were made between the unilateral and bilateral drainage groups in terms of the patients after ERCP procedure, clinical success, additional procedures, complications,
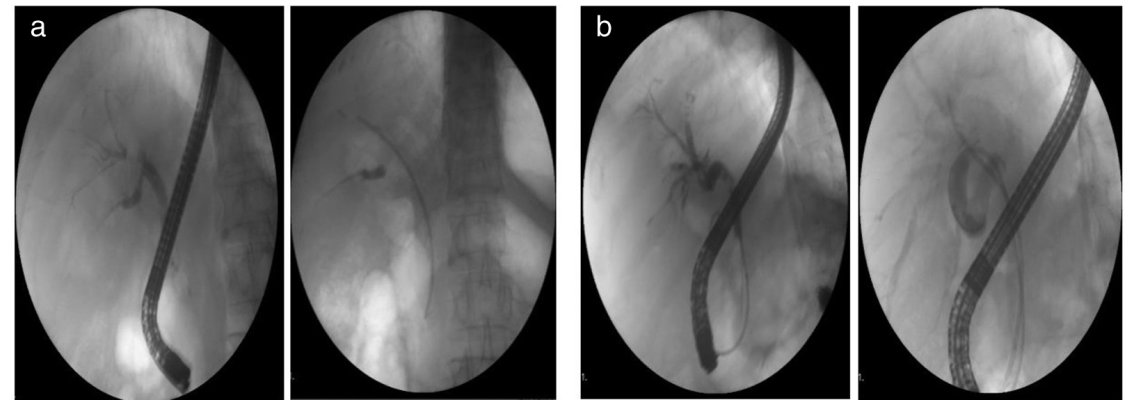

FIG. 2. a, b. Cholangiographic findings where RASD and RPSD with biliary anastomotic strictures were visualized at the initial ERCP. a) $7.0 \mathrm{Fr} \times 14 \mathrm{~cm}$ plastic stent was inserted into the RASD b) Two plastic stents were inserted into each of the RASD and RPSD, respectively $7.0 \mathrm{Fr} \times 14 \mathrm{~cm}$ and $16 \mathrm{~cm}$. 
procedures after clinical failure, hospitalization stay, follow-up time, number of ERCP sessions, mortality, and survival.

\section{Statistical Analysis}

Based on the post-hoc power analysis, the calculated power (1-beta) yielded 0.803 , considering type I error (alpha) of 0.05 , a total sample size of 155 , and an effect size of 0.5 for net success and the two-sided alternative hypothesis (H1).

The datasets were summarized as median (min-max), [mean \pm standard deviation], and count (percent). While chi-square analysis was used to compare group categories in terms of qualitative variables, the Mann-Whitney $U$-test was used to compare group categories in terms of quantitative variables. Whether the dataset followed normal distribution was examined by the Shapiro-Wilk test. A value of $P<.05$ was accepted as the statistical significance level. The IBM SPSS Statistics 25.0 package program was used in the analysis (IBM SPSS Corp; Armonk, NY, USA).

Multivariate Cox regression (hazard regression) analysis was applied to examine the effect of independent variables on the mortality variable. For categorical variables, the first category was accepted as the reference category. A value of $P<.05$ was accepted as the statistical significance level. The IBM SPSS Statistics 26.0 package program was used in the analysis.

\section{RESULTS}

\section{Patient Characteristics}

Our study was conducted by examining the data of $182 \mathrm{RL}$ LDLT patients with double anastomosis and anastomotic strictures. During follow-up, biliary anastomotic strictures occurred in approximately $60 \%(182 / 306)$ of patients with RL LDLT double anastomosis. The initial basic characteristics of the patients participating in the study are summarized in Table 1. One hundred fifty-five patients with double DDA, RL LDLT, for whom ERCP was technically successful, were demographically examined, and the average age of the patients was $46 \pm 15 ; 108$ of them $(70 \%)$ were male and $47(30 \%)$ were female. When the pre-transplant indication for transplantation was evaluated, it was seen that the most common cause was liver cirrhosis ( $81 \%$ ), followed by hepatocellular carcinoma (HCC) $(13 \%)$ and fulminant hepatitis $(6 \%)$. An examination of the etiological causes of liver cirrhosis revealed the hepatitis B virus (42\%), hepatitis C virus (9\%), alcohol (4\%), autoimmune liver disease (4\%), Wilson's disease (3\%), portal vein thrombus (2\%), Budd Chiari syndrome (4\%), cryptogenic (24\%), and combined disease $(7 \%)$. Considering the LT-related data, it was observed that the mean age of the patient donors who received RL LDLT was $30 \pm 10$ years, the mean duration of the operation was $9 \pm 3$ hours, and the warm and cold ischemia times were $48 \pm 26$ and $91 \pm 63$ minutes, respectively.

A few (8\%) patients who developed biliary stricture after LDLT were admitted with suspicion of acute cholangitis, while most of them presented with LFT elevation $(60 \%)$ and abnormal imaging findings $(28 \%)$. Very little of it manifested as one of their complaints, such as right upper-quadrant pain, fever, and itching
TABLE 1. Demographic and Baseline Patient Characteristics

\begin{tabular}{|c|c|}
\hline Parameters & Value $(\mathrm{n}=182)$ \\
\hline Age, years & $46 \pm 15$ \\
\hline \multicolumn{2}{|l|}{ Sex } \\
\hline Female & $55(30)$ \\
\hline Male & $127(70)$ \\
\hline \multicolumn{2}{|l|}{ Causes for LT } \\
\hline Liver cirrhosis & $147(81)$ \\
\hline Fulminant hepatitis & $12(7)$ \\
\hline Hepatocellular carcinoma & $23(13)$ \\
\hline \multicolumn{2}{|l|}{ Etiologies of liver cirrhosis } \\
\hline Hepatitis B virus & $77(42)$ \\
\hline Hepatitis $\mathrm{C}$ virus & $16(9)$ \\
\hline Alcohol & $8(4)$ \\
\hline Autoimmune & $8(4)$ \\
\hline Wilson's disease & $5(3)$ \\
\hline Portal vein thrombus & $3(2)$ \\
\hline Budd Chiari syndrome & $8(4)$ \\
\hline Cryptogenic & $43(24)$ \\
\hline Combined & $14(8)$ \\
\hline \multicolumn{2}{|l|}{ LT-related data } \\
\hline Donor age, years & $30 \pm 10$ \\
\hline Operation time, hours & $9 \pm 3$ \\
\hline Cold ischemia time, minutes & $91 \pm 63$ \\
\hline Warm ischemia time, minutes & $48 \pm 26$ \\
\hline Charlson comorbidity index & $4 \pm 2$ \\
\hline Duration to initial stricture, days & $272(1-3592)$ \\
\hline Suspected cholangitis & $14(8)$ \\
\hline \multicolumn{2}{|c|}{ Main manifestation of biliary stricture } \\
\hline Fever & $13(7)$ \\
\hline Pain & $6(3)$ \\
\hline Itching & $8(4)$ \\
\hline LFT abnormality & $101(56)$ \\
\hline Bile duct dilatation & $50(28)$ \\
\hline \multicolumn{2}{|c|}{ Laboratory findings before initial ERCP } \\
\hline $\mathrm{WBC}, 10^{3} / \mu \mathrm{L}$ & $6 \pm 4$ \\
\hline $\mathrm{CRP}, \mathrm{mg} / \mathrm{dL}$ & $4 \pm 8$ \\
\hline ALP, IU/L & $299 \pm 259$ \\
\hline GGT, IU/L & $341 \pm 331$ \\
\hline AST, IU/L & $71 \pm 69$ \\
\hline ALT, IU/L & $121 \pm 132$ \\
\hline Total bilirubin, $\mathrm{mg} / \mathrm{dL}$ & $3 \pm 4$ \\
\hline Direct bilirubin, mg/dL & $2 \pm 3$ \\
\hline
\end{tabular}

Data are given as mean \pm standard deviation, median(min.-max.), or $n(\%)$. 
TABLE 2. Fluoroscopy Findings and Treatment Data During the Initial ERCP

\begin{tabular}{lc}
\hline Initial ERCP Data & Value $(\mathrm{n}=155)$ \\
\hline Stricture morphology of RASD & $63(41)$ \\
Narrow & $4(3)$ \\
Wide & $1(1)$ \\
Separate & \\
Stricture morphology of RPSD & $63(41)$ \\
$\quad$ Narrow & $10(7)$ \\
Wide & $1(1)$ \\
Separate & \\
Angle between the proximal and distal ducts & $73(47)$ \\
$0-30^{\circ}$ & $1(1)$ \\
$>90^{\circ}$ & $3(2)$ \\
S shape & $141(91)$ \\
EST & $85(55)$ \\
Balloon dilatation at anastomotic stricture, mm & $25(16)$ \\
4 & $50(32)$ \\
6 & $10(7)$ \\
8 & $136(88)$ \\
ERCP with plastic stent & $7.1(7-10)$ \\
Diameter, Fr & $129(84)$ \\
7 & $6(4)$ \\
Lechnth, cm & $12.9(10-18)$ \\
\hline & $146(94)$ \\
\hline & \\
&
\end{tabular}

Data are given as mean \pm standard deviation, median (min.-max.), or $\mathrm{n}(\%)$.

(Table 1). The mean total bilirubin level before the first procedure was $3 \pm 4 \mathrm{mg} / \mathrm{dL}$, ALP 299 \pm 259 , GGT $341 \pm 331 \mathrm{IU} / \mathrm{L}$, and CRP $4 \pm 8 \mathrm{mg} / \mathrm{dL}$.

\section{Fluoroscopy Findings and Treatment Data During the Initial ERCP}

The ERCP procedure was performed in 182 patients with double anastomosis in whom anastomotic stricture and cholangitis were suspected. Technically, cannulation was achieved in a total of 155 $(85 \%)$ patients, which was at the next session for 9 of them. The patients for whom the cannulation was unsuccessful were given a PTBD procedure. The cannulated patients were imaged with balloon cholangiography under fluoroscopy for RASD, RPSD, and anastomotic stricture. The narrow type of stricture morphology was detected in $47 \%$ of the patients. The vast majority of anastomotic strictures in both the anterior and posterior branches were also narrow, at $41 \%$ and $40 \%$, respectively. Wide stricture morphology was 2.5 times higher compared to branches, in RPSD. EST was used in $91 \%$, biliary balloon dilatation in $55 \%$, and plastic stent in $88 \%$ of patients for whom initial ERCP was performed after direct or precut papillotomy. According to the angle between the proximal and distal ducts, stricture morphology in $47 \%$ of the cases was $0-30$ degrees (Table 2).

\section{The Comparison of Drainage Groups}

The mean age of the unilateral group was 45 , while that for the bilateral group was 47 years. While the female/male ratio was $31 / 85$ in the unilateral group, it was $12 / 27$ in the bilateral group. When both groups were compared in terms of clinical features (fever, pain, itching), no significant difference was found $(P=.329$, .832 , and .739 respectively). No significant results were found in the multivariate Cox regression analysis of the demographic and clinical characteristics.

The drainage groups was compared in terms of clinical success, additional treatment (EST, pre-incision, ballooning, stone removal), post-ERCP complication, need for additional treatment after clinical failure (ERCP, PTBD), follow-up success and failure, hospitalization stay, survival, and 6-month mortality (Table 3). During the initial ERCP procedure, 116 patients (unilateral) and 39 patients (bilateral) received drainage treatment. Due to the clinical failure in the follow-up period after the initial ERCP, stenting was increased in $34(29 \%)$ patients in the unilateral drainage group and they were switched to the bilateral drainage group. While the difference between the groups in terms of additional procedures such as EST, needle-knife papillotomy and balloon dilatation was significant $(P=.007, .038$, and .038 respectively), the difference in stone removal was not significant $(P=.692)$. While EST was higher in the bilateral drainage group, needle-knife papillotomy and balloon dilatation were higher in the unilateral group (52\% vs. $79 \%$, $47 \%$ vs. $18 \%$, and $47 \%$ vs. $45 \%$, respectively). Comparing in terms of post-ERCP complications, the difference was insignificant in terms of bleeding, pancreatitis, and cholangitis $(P=.162, .564$, and .999 respectively). Although the PTBD procedure performed after clinical failure was higher in the unilateral group (18\% vs. 10\%), it was not statistically significant $(P>.05)$. However, there was a clear difference in the unilateral group regarding the need for stent increase. Although the initial clinical failure in the 2 groups during follow-up was higher in the unilateral group (62\% vs. $41 \%)$, it was not statistically significant $(P=.999)$. However, PTBC requirement and stenting increase were higher in the unilateral group after clinical success and were statistically significant $(P<.001)$. While the number of stent-free follow-up patients was $4(5 \%)$ in the unilateral drainage group, it was $7(22 \%)$ in the bilateral group. A comparison of the clinical success indicators revealed that the change in the number of stents was more significant in the unilateral group $(P<.001)$, while the number of patients with stent reduction and stent-free follow-up was more significant in the bilateral group $(P<.001)$. However, when compared in terms of net success in the follow-up period, the difference between the 2 groups was significant (respectively $38 \%$ vs. $59, P=.034$ ) (Table 3 ).

In terms of hospital stay, the difference between both groups was not statistically significant ( 7 vs. 4 days, $P=.142$,). The followup time of both groups was 42 months and was equal. The passing time for stent replacement of both groups was 4 months and was equal $(P=.901)$. The requirement for ERCP sessions during follow-up was higher in the bilateral group, and this difference 
TABLE 3. The Comparison of Drainage Groups in Terms of Morbidity and Mortality

\begin{tabular}{|c|c|c|c|}
\hline Parameters & Unilateral, $(\mathrm{n}=116)$ & Bilateral, $(n=39)$ & $P$ \\
\hline Age, years & $45(15)$ & $47(13)$ & .624 \\
\hline \multicolumn{4}{|l|}{ Sex } \\
\hline Female & $31(27)$ & $12(31)$ & \multirow[t]{2}{*}{.625} \\
\hline Male & $85(73)$ & $27(69)$ & \\
\hline \multicolumn{4}{|l|}{ Clinical characteristics } \\
\hline Fever & $16(14)$ & $3(8)$ & .329 \\
\hline Pain & $5(5)$ & $2(6)$ & .832 \\
\hline Itching & $9(9)$ & $4(11)$ & .739 \\
\hline Initial clinical success & $81(70)$ & $32(82)$ & .201 \\
\hline \multicolumn{4}{|l|}{ After initial clinical failure } \\
\hline \multicolumn{4}{|l|}{ РТВC } \\
\hline A & $21(18)$ & $4(10)$ & \multirow[t]{2}{*}{.999} \\
\hline NA & $4(3)$ & $3(8)$ & \\
\hline Biliary stenting enhancement & $10(9)$ & $0(0)$ & - \\
\hline \multicolumn{4}{|l|}{ Additional procedures } \\
\hline EST & $59(60)$ & $30(77)$ & \multirow[t]{3}{*}{.007} \\
\hline Needle-knife papillotomy & $55(47)$ & $7(18)$ & \\
\hline Balloon dilatation, total & $55(47)$ & $17(44)$ & \\
\hline $4 \mathrm{~mm}$ & $15(27)$ & $5(29)$ & \multirow[t]{3}{*}{.038} \\
\hline $6 \mathrm{~mm}$ & $36(66)$ & $7(41)$ & \\
\hline $8 \mathrm{~mm}$ & $4(7)$ & $5(29)$ & \\
\hline Stone removal & $6(5)$ & $3(8)$ & .692 \\
\hline \multicolumn{4}{|l|}{ Post-ERCP complications } \\
\hline Bleeding & $18(16)$ & $2(5)$ & .162 \\
\hline Pancreatitis & $14(12)$ & $3(8)$ & .564 \\
\hline Cholangitis & $18(16)$ & $6(15)$ & .999 \\
\hline \multicolumn{4}{|c|}{$\begin{array}{l}\text { Change in follow-up in patients with clinical success(secondary } \\
\text { outcomes) }\end{array}$} \\
\hline РTBC & $16(20)$ & $5(16)$ & \multirow[t]{5}{*}{$<.001$} \\
\hline Stenting enhancement & $34(42)$ & $8(25)$ & \\
\hline No increase in stent count & $27(33)$ & $4(13)$ & \\
\hline Stent reduction & $1(1)$ & $7(22)$ & \\
\hline Stent-free follow-up & $4(5)$ & $7(22)$ & \\
\hline Net success (primary outcome) & $32(40)$ & $17(53)$ & .193 \\
\hline The passing time for stent replacement, months & $4(1-62)[10 \pm 13]$ & $4(1-49)[8 \pm 11]$ & .901 \\
\hline 6-month mortality & $10(9)$ & $1(3)$ & .293 \\
\hline Hospital stay, days & $7(1-69)[11 \pm 13]$ & $4(1-66)[11 \pm 17]$ & .142 \\
\hline Follow-up duration, months & $42(1-125)[46 \pm 33]$ & $42(1-70)[38 \pm 22]$ & .163 \\
\hline Number of ERCPs during follow-up & $5(0-24)[5 \pm 5]$ & $6(1-13)[6 \pm 3]$ & .049 \\
\hline
\end{tabular}

*Data are presented as median (min.-max.) [mean \pm standard deviation] and $\mathrm{n}(\%)$. A, applicable; N/A, not applicable.

was statistically significant $(P=.049)$ (Table 3). During followup, 10 patients in the unilateral group and a patient in the bilateral group did not survive. However, this difference was not statistically significant $(P=.293)$ (Table 3$)$ (Figure 3).

Nine of the patients who died had anastomotic stenosis as well as bile leakage. While 9 of the deaths resulted from sepsis due to bilioma, the remaining 2 patients died from $\mathrm{HCC}$ recurrence and cerebral infarction that developed after vascular graft thrombosis.

The multivariate Cox regression analysis did not yield significant results. There was no difference in survival between the 2 drainage techniques. 


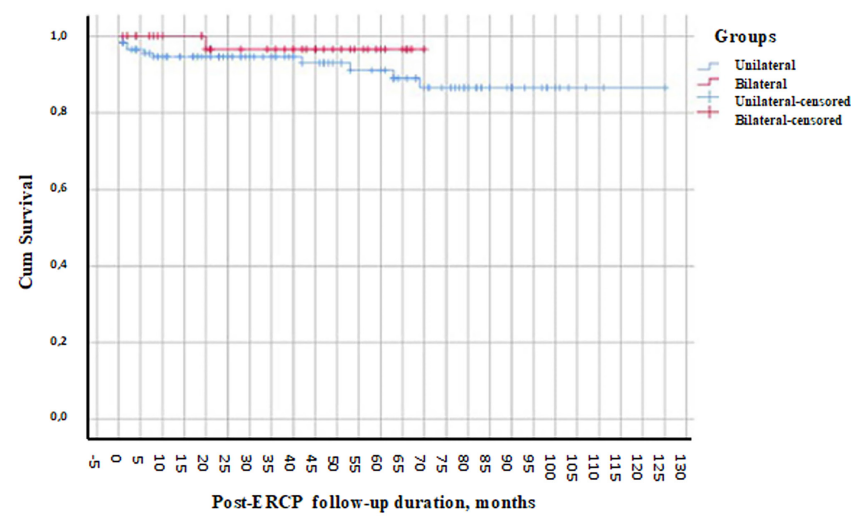

FIG. 3. Kaplan-Meier survival analysis. No significant difference was observed between the groups.

\section{DISCUSSION}

The most common and most important source of morbidity after LT is biliary strictures. It is known that most of this is composed of anastomotic strictures. Anastomotic strictures occur depending on a variety of causes. The primary treatment for the drainage problem is endoscopic biliary stenting. ${ }^{11}$ It is advocated by the literature that the number of stenting branches and the number of stents placed are decisive for optimal biliary drainage treatment. ${ }^{25}$ However, this also increases the processing time, sedation time, and operational complications. This situation prompted us to consider whether optimal drainage would be possible by reducing the number of branches and the number of stents, and we were directed to new research in this regard. However, there is no adequate study on this subject, especially among patients who have undergone liver transplantation. Drainage comparison studies were performed in patients with mostly malignant hepatic hilar obstruction. Drainage of the whole liver has been the subject of controversy. Unilateral and bilateral drainages have been compared in terms of early complications such as stenting success, clinical success, and contrast-related cholangitis, with contradictory results. In addition, considering the disadvantages of the greater technical difficulty of bilateral drainage, there were more complications necessitating more procedures. This has revealed the need the comparison with unilateral drainage. ${ }^{27,28}$ In our study, a total of 2 groups, unilateral and bilateral, were compared based on various variables.

The first treatment options for anastomotic strictures include EST, endoscopic treatment including balloon dilation, and stenting. ${ }^{29,30}$ Strictures become more complicated with an increased number of anastomoses, rendering the resolution more difficult, ${ }^{31}$ and the simultaneous use of several endoscopic treatment options becomes inevitable. While stent placement after balloon dilation enables larger diameter stent placement, it also brings with it the risk of more complications. ${ }^{32}$ However, there is a study that says otherwise. ${ }^{33}$ In our study, additional procedures such as EST, needle-knife papillotomy, and balloon dilatation were used as primary treatment options. In terms of these additional procedures, the groups were compared and the difference between them was significant. Biliary balloon dilatation requirement was higher in the unilateral group than in the bilateral group. It can be explained by the harder anastomotic strictures in the unilateral drainage group.

Since endoscopic stenting is the primary treatment option in biliary anastomotic strictures, ERCP procedure was performed for these patients for more than one session during the follow-up and drainage was provided with stenting in approximately three-quarters $(80 \%)$ of the patients. In a previous study, the optimal treatment of the drainage problem has been shown to be endoscopic stenting. ${ }^{14}$ The higher clinical success seen in bilateral stenting was supported by the results showing that multiple stent use was more successful than single stents in previous studies. ${ }^{34,35}$ In our study, the difference created by patients resolved with bilateral stenting was statistically significant. The biliary drainage problem was successful in treating $38 \%$ of all patients only with unilaterally placed stenting.

When the 2 groups were compared in terms of stone removal, the difference was not significant in the unilateral group. In the later stages of the follow-up period, approximately $55.8 \%$ of the total patients in both groups of patients in whom the drainage problem was faced recurrence, and the problem was solved by performing the ERCP process by increasing the number of stents in the majority $(37 \%)$ and performing PTBD for half of them. The drainage problem of patients in the unilateral group was found to be approximately 1.5 times higher than in the bilateral group. However, while approximately one-tenth of the unilateral group was transitioned to the bilateral group, all patients with drainage problems in the bilateral group were resolved with the PTBD procedure. Clinical success rates were compared between the 2 groups, but there was no statistically significant difference. Although this situation improves drainage as the stent count increases in the first period, the flow of bile is disrupted by sludge or stones forming and developing into an obstruction during follow-up, making treatment more difficult. In the patients with low stent count, almost less sludge or stone development (5\% and $8 \%$, respectively) led to a nearly similar result between better clinical outcomes. The relationship between the stent count and duration, and the biliary obstruction caused by biliary stones and sludge, confirm our results. ${ }^{27,36,37}$

The complications related to the procedure are higher in patients with greater stent count and longer duration of procedure. Cholangitis may occur, caused by the bile sludge formed as a result of deterioration of bile flow due to the high stent count, or later, when the stent does not provide sufficient drainage. ${ }^{38}$ When compared to post-ERCP complications, the difference was insignificant in terms of bleeding, pancreatitis, and cholangitis. The results of a previous study ${ }^{39}$ with similar complication rate between precut papillotomy and standard cannulation correlate with our results.

Although the number of PTBD procedures performed after clinical failure was more in the unilateral group (18\% vs. 10\%), it was not statistically significant. However, there was a clear difference in unilateral group regarding the need for stent increase. This indicates that transition to bilateral drainage is necessary in cases where adequate drainage is not provided. For this, it is necessary to increase 
the stent count with ERCP and/or PTBD processes. ${ }^{40}$ Although there is no consensus on the ideal drainage pathway, ${ }^{41}$ it shows that bilateral drainage is superior. However, when the groups were evaluated for net success, it was observed that the success of the unilateral drainage group was at a considerable value even though there was statistically at a significantly higher level in the bilateral group. In terms of hospital stay, the statistically insignificant differences between both groups are thought to be associated with low clinical success in the unilateral drainage group. There was no difference between the groups in terms of survival. The results of previous studies are also compatible with our results, in that there was no significant difference between the 2 drainage groups both in terms of the hospitalization time and survival rate. ${ }^{23,38}$

Efforts are made first to solve the drainage problem of the unilateral or bilateral drainage group, using ERCP, by increasing stent count and/or balloon dilatation. The PTBD procedure is a secondary method preferred after clinical or technical failure of ERCP, because of its more invasive nature and higher potential complications. ${ }^{42}$ In the follow-up period, the number of ERCP procedures was higher in the bilateral group, and this difference was statistically significant. After initial clinical failure, the need for the PTBD procedure was much higher than for the ERCP procedure, and higher in the unilateral group than in the bilateral group. The number of ERCP procedures required was higher in the unilateral group, and this difference was also statistically significant. After the clinical failure that occurred during the follow-up period, there was a clear advantage of 2-fold ERCP processing as the need for additional processing. It was similar between the 2 groups. The reason for this is that although the problem of drainage, which continued in the unilateral group or that occurred later, gave rise to the need for ERCP, attempts were made to resolve the problem PTBD in very tight strictures that technically could not be overcome with the guide. In the follow-up period, the reason that the ERCP process is superior to PTBD is due to the need for revision of the clogged stents.

The greatest limitation of the study is its retrospective nature It was not possible to synchronize the groups, since they are anatomically complex, and ERCP and/or PTBD and stent replacement cannot be performed regularly.

As a result, in addition to the lower initial clinical success rate in the unilateral group, stent enhancement and the need for PTBC after clinical success and failure were higher, and stent reduction and stent-free follow-up were less in the follow-up of patients with clinical success compared to the bilateral group. While mortality and length of hospital stay were numerically lower, net success was statistically higher in the bilateral group. Although the success of unilateral drainage is lower in patients with difficult bilateral drainage, it can be applied. The success can be increased with the complementary PTBD procedure. According to the multivariate Cox regression analysis, there was no difference between the 2 groups in terms of survival.

In conclusion, in this study, successful bilateral drainage was achieved in most of the patients by performing repetitive ERCP and/or additional procedures (biliary balloon dilatation, PTBD). Only one-third had clear success with unilateral drainage. The conditions must be actively enforced for bilateral drainage in patients with biliary anastomotic stricture following RL LDLT. In patients with biliary anastomotic strictures in whom bilateral drainage is not possible, unilateral drainage may be recommended with maximum stent placement after biliary balloon dilatation, depending on the degree of the stricture. However, there is a need for prospective, randomized controlled trials with well-designed, large-scale, longer-term follow-up to reduce the contradictions in studies, validate our results, and obtain more reliable evidence.

Patient Consent for Publication: Informed consent was obtained from the patients.

Data-sharing Statement: The data that support the findings of this study are available from the corresponding author upon reasonable request.

Author Contributions: Concept - Y.F.Ç.; Design - Y.F.Ç.; Supervision - M.A.E.; Resources - Y.F.Ç.; Data Collection and/or Processing - O.S., M.A.E.; Analysis and/or Interpretation - Y.F.Ç., O.Y., Y.B., A.K.A.; Literature Review - Y.F.Ç., M.A.E., O.S.; Writing - Y.F.Ç.; Critical Review - K.B.S., S.Y.

Conflict of Interest: The authors have no conflicts of interest to declare.

Funding: The authors declared that this study had received no financial support.

\section{REFERENCES}

1. Shukla A, Vadeyar H, Rela M, Shah S. Liver transplantation: East versus West. J Clin Exp Hepatol. 2013;3(3):243-253. [CrossRef]

2. Berg CL, Gillespie BW, Merion RM, et al. Improvement in survival associated with adult-to-adult living donor liver transplantation. Gastroenterology. 2007;133(6):18061813. [CrossRef]

3. Malagó M, Rogiers X, Broelsch CE. Liver splitting and living donor techniques. $\mathrm{Br}$ Med Bull. 1997;53(4):860-867. [CrossRef]

4. Northup PG, Abecassis MM, Englesbe MJ, et al. Addition of adult-to-adult living donation to liver transplant programs improves survival but at an increased cost. Liver Transpl. 2009;15(2):148-162. [CrossRef]

5. Pomfret EA, Fryer JP, Sima CS, Lake JR, Merion RM. Liver and intestine transplantation in the United States, 1996-2005. Am J Transplant. 2007;7(5 Pt 2):1376-1389. [CrossRef]

6. Hwang S, Lee SG, Sung KB, et al. Long-term incidence, risk factors, and management of biliary complications after adult living donor liver transplantation. Liver Transpl. 2006;12(5):831-838. [CrossRef]

7. Liu CL, Lo CM, Chan SC, Fan ST. Safety of duct-to-duct biliary reconstruction in right-lobe live-donor liver transplantation without biliary drainage. Transplantation. 2004;77(5):726-732. [CrossRef]

8. Santosh Kumar KY, Mathew JS, Balakrishnan D, et al. Intraductal transanastomotic stenting in duct-to-duct biliary reconstruction after living-donor liver transplantation: a randomized trial. J Am Coll Surg. 2017;225(6):747-754. [CrossRef]

9. Scanga AE, Kowdley KV. Management of biliary complications following orthotopic liver transplantation. Curr Gastroenterol Rep. 2007;9(1):31-38. [CrossRef]

10. Thuluvath PJ, Atassi T, Lee J. An endoscopic approach to biliary complications following orthotopic liver transplantation. Liver Int. 2003;23(3):156-162. [CrossRef]

11. Sharma S, Gurakar A, Jabbour N. Biliary strictures following liver transplantation: past, present and preventive strategies. Liver Transpl. 2008;14(6):759-769. [CrossRef]

12. Kim ES, Lee BJ, Won JY, Choi JY, Lee DK. Percutaneous transhepatic biliary drainage may serve as a successful rescue procedure in failed cases of endoscopic therapy for a post-living-donor liver transplantation biliary stricture. Gastrointest Endosc. 2009;69(1):38-46. [CrossRef]

13. Kato H, Kawamoto H, Tsutsumi K, et al. Long-term outcomes of endoscopic management for biliary strictures after living-donor liver transplantation with duct-to-duct reconstruction. Transpl Int. 2009;22(9):914-921. [CrossRef]

14. Hsieh TH, Mekeel KL, Crowell MD, et al. Endoscopic treatment of anastomotic biliary strictures after living-donor liver transplantation: outcomes after maximal stent therapy. Gastrointest Endosc. 2013;77(1):47-54. [CrossRef] 
15. Fan ST, Lo CM, Liu CL, Tso WK, Wong J. Biliary reconstruction and complications of right lobe live donor liver transplantation. Ann Surg. 2002;236(5):676-683. [CrossRef]

16. Tsujino T, Isayama H, Kogure H, et al. Endoscopic management of biliary strictures after living donor liver transplantation. Clin J Gastroenterol. 2017;10(4):297-311. [CrossRef]

17. Wadhawan M, Kumar A. Management issues in post living donor liver transplant biliary strictures. World J Hepatol. 2016;8(10):461-470. [CrossRef]

18. Morelli G, Fazel A, Judah J, et al. Rapid-sequence endoscopic management of posttransplant anastomotic biliary strictures. Gastrointest Endosc. 2008;67(6):879-885. [CrossRef]

19. Morelli J, Mulcahy HE, Willner IR, Cunningham JT, Draganov P. Long-term outcomes for patients with post-liver transplant anastomotic biliary strictures treated by endoscopic stent placement. Gastrointest Endosc. 2003;58(3):374-379. [CrossRef]

20. Thuluvath PJ, Pfau PR, Kimmey MB, Ginsberg GG. Biliary complications after liver transplantation: the role of endoscopy. Endoscopy. 2005;37(9):857-863. [CrossRef]

21. Rerknimitr R, Sherman S, Fogel EL, et al. Biliary tract complications after orthotopic liver transplantation with choledochocholedochostomy anastomosis: endoscopic findings and results of therapy. Gastrointest Endosc. 2002;55(2):224-231. [CrossRef]

22. Boeva I, Karagyozov PI, Tishkov I. Post-liver transplant biliary complications: current knowledge and therapeutic advances. World J Hepatol. 2021;13(1):66-79. [CrossRef]

23. You MS, Paik WH, Choi YH, et al. Optimal biliary drainage for patients with biliary anastomotic strictures after right lobe living donor liver transplantation. Liver Transpl. 2019;25(8):1209-1219. [CrossRef]

24. Zoepf T, Maldonado-Lopez EJ, Hilgard P, et al. Balloon dilatation vs. balloon dilatation plus bile duct endoprostheses for treatment of anastomotic biliary strictures after liver transplantation. Liver Transpl. 2006;12(1):88-94. [CrossRef]

25. Costamagna G, Pandolfi M, Mutignani M, Spada C, Perri V. Long-term results of endoscopic management of postoperative bile duct strictures with increasing numbers of stents. Gastrointest Endosc. 2001;54(2):162-168. [CrossRef]

26. Park JK, Yang JI, Lee JK, et al. Long-term outcome of endoscopic retrograde biliary drainage of biliary stricture following living donor liver transplantation. Gut Liver. 2020;14(1):125-134. [CrossRef]

27. De Palma GD, Galloro G, Siciliano S, Iovino P, Catanzano C. Unilateral versus bilateral endoscopic hepatic duct drainage in patients with malignant hilar biliary obstruction: results of a prospective, randomized, and controlled study. Gastrointest Endosc. 2001;53(6):547-553. [CrossRef]

28. Fukasawa M, Takano S, Shindo H, et al. Endoscopic biliary stenting for unresectable malignant hilar obstruction. Clin J Gastroenterol. 2017;10(6):485-490. [CrossRef]
29. Gómez CM, Dumonceau JM, Marcolongo M, et al. Endoscopic management of biliary complications after adult living-donor versus deceased-donor liver transplantation. Transplantation. 2009;88(11):1280-1285. [CrossRef]

30. Tsujino T, Isayama H, Sugawara $\mathrm{Y}$, et al. Endoscopic management of biliary complications after adult living donor liver transplantation. Am $J$ Gastroenterol. 2006;101(10):2230-2236. [CrossRef]

31. Koneru B, Sterling MJ, Bahramipour PF. Bile duct strictures after liver transplantation: a changing landscape of the Achilles' heel. Liver Transpl. 2006;12(5):702-704. [CrossRef]

32. Kulaksiz H, Weiss $\mathrm{KH}$, Gotthardt $\mathrm{D}$, et al. Is stenting necessary after balloon dilation of post-transplantation biliary strictures? Results of a prospective comparative study. Endoscopy. 2008;40(9):746-751. [CrossRef]

33. Arikan T, Emek E, Bozkurt B, et al., eds. Does multiple bile duct anastomosis in living donor liver transplantation affect the postoperative biliary complications? Transplant Proc. 2019;51(7):2473-2477. [CrossRef]

34. Chang JH, Lee IS, Choi JY, et al. Biliary stricture after adult right-lobe living-donor liver transplantation with duct-to-duct anastomosis: long-term outcome and its related factors after endoscopic treatment. Gut Liver. 2010;4(2):226-233. [CrossRef]

35. Tashiro H, Itamoto T, Sasaki T, et al. Biliary complications after duct-to-duct biliary reconstruction in living-donor liver transplantation: causes and treatment. World $J$ Surg. 2007;31(11):2222-2229. [CrossRef]

36. Di Giorgio P, Manes G, Grimaldi E, et al. Endoscopic plastic stenting for bile duct stones: stent changing on demand or every 3 months. A prospective comparison study. Endoscopy. 2013;45(12):1014-1017. [CrossRef]

37. Sohn SH, Park JH, Kim KH, Kim TN. Complications and management of forgotten long-term biliary stents. World J Gastroenterol. 2017;23(4):622-628. [CrossRef]

38. Iwano $\mathrm{H}$, Ryozawa $\mathrm{S}$, Ishigaki $\mathrm{N}$, et al. Unilateral versus bilateral drainage using self-expandable metallic stent for unresectable hilar biliary obstruction. Dig Endosc. 2011;23(1):43-48. [CrossRef]

39. Tang SJ, Haber GB, Kortan P, et al. Precut papillotomy versus persistence in difficult biliary cannulation: a prospective randomized trial. Endoscopy. 2005;37(1):58-65. [CrossRef]

40. Lorenz JM, eds. Management of malignant biliary obstruction. Semin Intervent Radiol. 2016;33(4):259-267. [CrossRef]

41. Baer HU, Rhyner M, Stain SC, et al. The effect of communication between the right and left liver on the outcome of surgical drainage for jaundice due to malignant obstruction at the hilus of the liver. HPB Surg. 1994;8(1):27-31. [CrossRef]

42. Enestvedt B, Enestvedt C, Faigel D, Orloff S. ERCP is superior to PTC in the management of biliary stricture following orthotopic liver transplantation: 129. Am J Gastroenterol. 2010;105:S48-S49. 